\title{
Exploring the Effects of the Computational Experiment Approach to the Epistemic Beliefs, the Motivation, the Use of Modeling Indicators and Conceptual Understanding in Three Different Computational Learning Environments
}

\author{
Sarantos Psycharis ${ }^{1}$ \\ ${ }^{1}$ Faculty of Education, Liverpool Hope University, UK \\ Correspondence: Sarantos Psycharis, Liverpool Hope University, L169JD, UK. Tel: 44-151-291-3072. E-mail: \\ psychas@hope.ac.uk
}

Received: December 28, 2012 Accepted: January 14, 2013 Available online: February 4, 2013

doi:10.11114/jets.v1i1.32

URL: http://dx.doi.org/10.11114/jets.v1i1.32

\begin{abstract}
Contemporary teaching and learning approaches expect students -at any level of education- to be active producers of knowledge. This leads to the need for creation of instructional strategies, learning environments and tasks that can offer students opportunities for active learning. Research argues that one of the most meaningful and engaging forms of active learning is modelling, that is using computational environments to build representational and epistemological models of the phenomena that are being studied, following the essential features of inquiry based science and mathematics education. The aim of the article is to investigate the impact of the computational experiment approach on: a) students' learning performance, b) the use of modelling indicators c) the motives and d) the scientific epistemic beliefs. K-12 students in a Greek school participated in the experiment and the methodology of the computational experiment was implemented using three software tools, namely: the Modellus software, the Interactive Physics (IP) software and the Easy Java Simulator Software (EJS), in order to study the concept of the simple harmonic motion (equations of motion, dynamics and energy consideration). All applications were developed using the essential features of inquiry based science education in the framework of the computational approach methodology and the model was considered as the fundamental instruction unit. The findings suggest that the inquiry based computational experiment using Easy Java Simulator(EJS) is more effective in enhancing the conceptual understanding of students as well as the use of modelling indicators, and these results may have implications for the effectiveness of the computational experiment methodology when it is combined with the EJS Tools.
\end{abstract}

Keywords: science education, models, motives, simulation, epistemological beliefs

\section{Introduction}

\subsection{Inquiry Based Science Education (IBSE) and Models}

The field of science education research is concerned with the development of high-level skills like concept construction, modelling, problem solving, cognitive-metacognitive skills and scientific/conceptual processes. Science education is also concerned with helping students to develop knowledge about physical realities that is in line with scientific knowledge (Halloun, 2006).

Inquiry based learning has been treated as a means of improving science learning in different countries (Bybee et al., 2008). Inquiry can be defined as 'the intentional process of diagnosing problems, critiquing experiments, distinguishing alternatives, planning investigations, researching conjectures, searching for information, constructing models, debating with peers, and forming coherent arguments'. The above is in alignment with research in science education (Bell et al., 2004) and is considered as a way to implement the science education research methodology in schools (Levy et al., 2010).

Inquiry is also a pedagogical method or teaching strategy, adopted by science teachers when they design learning activities that allow students to observe experiments and review what is known in light of evidence (Minner et al., 2010). Teaching science by inquiry requires communicating not only scientific information but also the abilities 
to do inquiry and, more importantly, a deep understanding of the nature of scientific inquiry is essential as it should be considered as a set of instructional strategies aiming at developing high level cognitive abilities.

Developing inquiry-based learning environments using computational science seems to be an essential research issue in science education. Bell, Urhahne, Schanze, and Ploetzner (2010), identified nine main science inquiry processes supported by different computational environments that could be used in inquiry-based science education (IBSE), namely: orienting and asking questions; generating hypotheses; planning; investigating; analyzing and interpreting; exploring and creating models; evaluating and concluding; communicating; predicting. The nine inquiry tools of Bell et al. (2010) are closely related to the essential features of inquiry (Assay \& Orgill, 2010), namely: Question (Learner engages in scientifically oriented questions), Evidence (Learner gives priority to evidence), Analysis (Learner analyses evidence), Explain (Learner formulates explanations from evidence), Connect (Learner connects explanations to scientific knowledge) and Communicate (Learner communicates and justifies explanations). There is a close relation between the essential features of inquiry and the nine tools proposed by (Bell et al., 2010). We notice that modelling is essential both as an inquiry tool and as an inherent inquiry feature. Then, the computational experiment approach (CE) seems pervasive in all inquiry processes since it is a fundamental component in model development.

\subsection{The Pedagogical Content Knowledge (PCK)}

PCK connects content and pedagogical knowledge facilitating teachers to create an inspiring learning environment for their students. Furthermore, it does not only stand for teachers' internal construction but also for a representation of their actions in the classroom as well as for their justifications. Shulman (1987) included PCK in the 'knowledge base of teaching' that consists of three content-related categories (content knowledge, PCK, curriculum knowledge) and four other categories (general pedagogy, learners and their characteristics, educational contexts, and educational purposes) (Valanides \& Angeli, 2005). In particular, ICT (Information and Communication Technologies) and Computer/Computational Science (CS)-related PCK is defined as knowing how to: a) detect/recognise topics related to concepts that learners cannot readily understand and that teachers cannot teach or effectively present in the classroom through use of ICT tools. In this way, the significance of engagement with ICT tools in the teaching process is highlighted, b) detect appropriate representations for transforming the content to be taught into forms that are pedagogically powerful and difficult to be supported by traditional means, c) select ICT-CS tools with appropriate features to afford the above content representations or transformations, d) detect teaching elements associated with the use of ICT tools, such as the application of ideas that cannot be experienced in real life, interactive learning, dynamic and contextually dependent feedback, authentic and adaptive learning to address learners' unique needs, e) ensure learners' engagement with learning activities in a pedagogically appropriate way in the classroom.

\subsection{The Computational Experiment and Modelling}

Over the past decade, increasing importance and attention have been attached to the potential for the new technologies of ICT-CS to improve teaching and learning in schools (Barton \& Haydn, 2006). Although a variety of approaches have been adopted over the years to prepare and support teachers in integrating ICT-CS in classroom practices, the results have not always been positive (Rodrigues, 2003). According to Piet Lijnse (Girep, 2006, http://www.girep2006.nl/, Modeling in Physics and Physics Education, Access October 11, 2012), focus on modelling is largely due to the following reasons. The first one is related to the recent constructivist attention to conceptions that students bring to the classroom. A second is the present emphasis on the role of philosophy in science education, which has resulted in stressing the importance of the nature of scientific models. According to Hestenes (1999) traditional physics courses lay heavy emphasis on problem solving and this results in directing student attention to problems and their solutions as units of scientific knowledge. Modelling theory tells us that these are the wrong units; the correct units are the models. Problem solving is important, but it should be subservient to modelling. Hestenes (1999), states that most physics problems are solved by constructing or selecting a model, from which the answer to the problem is extracted through model-based inference. In a profound sense the model provides the solution to the problem. Thus, an emphasis on models and modelling simplifies the organization of a problem in physics into understandable units. Directly connected to that approach, is the computational physics approach (CP). Some of the crucial components of (CP) are the abstraction of a physical phenomenon to a conceptual model and its translation into a computational model that can be validated. This leads us to the notion of the computational experiment (CE) according to which the model and the computer take the place of the 'classical' experimental set-up, and simulation replaces the experiment as such. 
Landau, Páez, and Bordeianu (2008) emphasize that computational experiment focuses on the form of a problem to be solved, and the components that constitute the solution are separated according to the scientific problem-solving paradigm: a. Problem (from science), b. Modelling (mathematical relations between selected entities and variables), c. Simulation Method (time driven, event driven, stochastic), d. Development of algorithm, e. Implementation of the algorithm (using Java, EJS, Mathematica, Fortran etc) and f. Assessment and Visualization through exploration of the results and comparison with real data. In this framework, being able to transform a theory into an algorithm requires significant theoretical insight, detailed physical and mathematical understanding as well as a mastery of the art of programming and of the actual debugging, testing, and organization of scientific programs which are analogous to experimentation, with the numerical simulations of nature being essentially virtual experiments (Psycharis, 2011).

In order to describe discovery/inquiry based learning as a search process Shunn and Klahr (1995) and Klahr and Dunbar (1998) introduced both the hypothesis and the experimental spaces in scientific discovery/inquiry learning. In their model the hypothesis space contains the rules and variables describing the specific domain, while the experimental space consists of all experiments that can be implemented within this domain. Psycharis (2011) extended these spaces in order to include the computational experiment approach and suggested three spaces for the computational experiment, namely:

1. The hypotheses space: the students in cooperation with the teacher, decide, clarify and state the hypotheses of the problem to be studied, as well as the variables and concepts to be used and the relations between them.

2. The experimental space: the computational experiment, including modeling and simulation based on discovery/inquiry learning activities for the problems under study, actually takes place. Thus, learners are engaged in the scientific method.

3. The prediction space: the results, conclusions or solutions formulated in the experimental space are checked through the analytical (mathematical) solution as well as through real world data helping learners to predict other phenomena.

\subsection{Modelling Indicators}

Modelling environments are based on a model which usually corresponds to a theory and allow learners to actually build models. Despite the fact that modelling and simulation are quite different issues, there is some confusion over them and thus certain points need to be clarified.

According to Hestenes (1999) model specification is composed by a model which describes (or specifies) four types of structure, each with internal and external components, considered as modeling indicators:

1. systemic structure which specifies: composition (internal parts of the system), environment (external agents linked to the system), connections (external and internal causal links)

2. geometric structure which specifies: position with respect to a reference frame (external geometry), configuration (geometric relations among the parts)

3. temporal structure which specifies: change in state variables (system properties), by explicit functions or implicit functions of time represented by differential equations in accordance to interaction laws

4. interaction structure which specifies interaction laws expressing interactions among causal links, usually as function of state variables

\subsection{Epistemic Beliefs}

Studies on epistemic (epistemological) beliefs in learning began by Perry (1970) who explored students' interpretation of educational experiences. This exploration paved the way for the theory of epistemological development (Hofer \& Pintrich, 1997). Schommer (1990) developed an Epistemological Beliefs Questionnaire (EBQ) which consisted of 63 items. In one of Schommer's studies, twelve subsets of items were determined and factor analysis was conducted. The factor analysis indicated that the twelve subsets of items were loaded onto four factors: Innate Ability, Simple Knowledge, Quick Learning and Certain Knowledge. The Schommer's dimensions were found to be somewhat problematic by Hofer and Pintrich (1997). According to Hofer and Pintrich (1997), fixed ability and quick learning are not epistemological dimensions and do not focus on the nature of knowledge and knowing (Kurt, 2009).

Hofer and Pintrich (1997) suggested that epistemic beliefs should involve four dimensions: "certainty" of knowledge (e.g. knowledge is fixed or continuously developing), "simplicity" of knowledge (e.g. knowledge is absolute or relative), "source" of knowing (e.g. knowledge is handed down by authority or can be challenged), and "justification" of knowing (e.g. knowledge can be learned from critical thinking processes or from existing 
facts). In addition, these four dimensions represent two general areas: Beliefs about the nature of knowledge and beliefs about the nature of knowing. A continuing scale ranging from absolutist beliefs about knowledge (i.e. knowledge is certain and stable) to sophisticated beliefs relevant to the idea that knowledge is complex, tentative, and actively constructed is associated with every dimension (Kienhues et al., 2008; Tsai et al., 2011).

Certainty of Knowledge and Simplicity of Knowledge reflect beliefs about the nature of knowledge while the Source of Knowledge and Justification for Knowing reflect beliefs about the nature of knowing. The beliefs about Certainty of Knowledge were explained as absolute truth existing with certainty (i.e. less sophisticated) and as knowledge being tentative and evolving (i.e. more sophisticated). At the lower level of beliefs about Simplicity of Knowledge, knowledge is explained as discrete, concrete and knowable facts whereas at the higher level, knowledge is explained as relative, contingent, and contextual. At the level of less sophisticated beliefs about Source of Knowledge, individuals believe that knowledge originates outside the self and resides in external authority whereas at the level concerning more sophisticated beliefs about Source of Knowledge, individuals believe that knowledge is constructed by the knower in interaction with others. Justification for the knowing dimension examines how individuals evaluate knowledge (Hofer \& Pintrich, 1997; Kurt, 2009). Thus, at lower levels individuals use the authority and observation rather than experiments, data and rules of inquiry which are mainly employed at higher levels to justify meaning (Hofer, 2000).

The study of epistemic beliefs has become a prominent line of inquiry in educational psychology, science and mathematics, and a growing body of evidence shows that students' beliefs about knowledge and knowing are linked to various facets of their learning (e.g. Muis \& Franco, 2009; Schommer, 1993).

\subsection{Motives}

Social cognitive theory, developed by Bandura (2006) and extended by others (e.g., Pajares \& Schunk, 2001) construes human functioning as a series of reciprocal interactions among personal characteristics, environmental contexts, and behaviors. According to social cognitive theory, self-regulation positively affects students' learning as it is related to motivational and behavioural understanding, monitoring and controlling. It is important that motivation constitutes an internal state that directs students to goal achievement (Glynn et al., 2011).

According to Pintrich and Schunk (2002), successful learning -in the meaning of conceptual change and meaningful learning- is mainly influenced by the cognitive residual of students, by previous knowledge and learning strategies, by students motivation (e.g. interest in the subject), by subject-specific self-concept, and by classroom contextual factors.

The study of motivation by science education researchers attempts to explain why students strive for particular goals when learning science, how intensively they strive, how long they strive, and what feelings and emotions characterize them in the process (Glynn \& Koballa, 2006; Glynn et al., 2009). The role of motivation in influencing expertise is expected to be critical in any domain (Taasoobshirazi \& Carr, 2009). Students who are highly motivated engage in behaviors and practice that lead to more expert knowledge and skills and, ultimately, to high performance (Ericsson, 2006).

Important elements that need to be considered in the exploration of students' motives to engage with science are intrinsic motivation, extrinsic motivation, task relevancy, self-determination, self-efficacy, and assessment anxiety (e.g. Glynn \& Koballa, 2006). Motivation to perform a task for its own sake is intrinsic, whereas motivation to perform a task as a means to an end is extrinsic (Ryan \& Deci, 2000). Students who are intrinsically motivated work on a task because they find it interesting whereas students who are extrinsically motivated work on a task to attain a desirable outcome such as a high grade. However, both types of motivation contribute to students' success in their courses (Ryan \& Deci, 2000).

According to Pintrich and Schunk (2002), motivation is the process whereby goal-directed activity is instigated and sustained The following variables, which are typical operational indices in motivational research, are central features of this definition (1) Task choice (i.e. selection of a task under free choice conditions), (2) Effort (i.e. high effort, particularly on difficult material), (3) Persistence (i.e. working for a longer time, particularly when one encounters obstacles), and (4) Achievement (i.e. increasing the above elements is expected to raise task achievement) (Rotgans, 2009).

\subsection{Modellus - Interactive Physics Software-easy Java Simulator}

Interactive Physics (IP) TM, the educational software developed by Design Simulation Technologies, makes it easy to observe, discover, and explore the physical world through exciting simulation. This easy-to-use program will support the most basic and the most complex topics in STEM education (http://www.design-simulation.com/ip/index.php). The IP environment has many characteristics similar to Object 
Oriented programming, but there are not many chances to write the model in mathematical forms. IP provides many tools to visualize objects but the degrees of freedom are rather limited compared to other software.

Modellus Software (http://modellus.fct.unl.pt/) is a computational environment that allows the construction of models of simulation of physical and mathematical phenomena using mathematical equations. Learners construct the mathematical model to represent the psychical phenomenon using specific operations provided by the Modellus software (derivatives, integrals, differential equations).

The reason for treating Easy Java Simulations (EJS) as an authoring tool specifically designed for the creation of interactive simulations in Java is twofold. Firstly, it makes the creation of the view of a simulation, that is, its graphical part- a process requiring technical expertise in programming computer graphics- less complicated. Secondly, the use of EJS results in less elaborate scientific descriptions of the investigated phenomenon. In other words, the structure provided for the creation of the simulation model is simplified while there are simple steps to implement issues from numerical analysis and random processes. Easy Java Simulations can be run under any operating system that supports a Java Virtual Machine. All information necessary for EJS can be found at http://fem.um.es/Ejs (Last Access, October 5th, 2012).

\section{Method}

\subsection{Sample}

Ninety three (N=93) K-12 students enrolled in the Physics Course at upper secondary level in a Greek School participated in this research. Students were divided in three classes. One class, Class A, ( $N=31$ students) was taught using the Interactive Physics Software combined with the traditional lecture, class B $(\mathrm{N}=31)$ was taught using the Modellus software combined with the traditional lecture, and class $\mathrm{C}(\mathrm{N}=31)$ was taught using the EJS software combined with the traditional lecture. All classes had the same teacher and students attended the course "Mechanical and Electrical Oscillations". Participants declared that they would take Greek University entrance exams to follow studies in the fields of engineering, science and medicine. Thus, they all were motivated to acquire and develop scientific skills as well as to get good grades.

\subsection{Materials and Procedure}

Four factors, namely Certainty, Source, Development and Justification that assess students' beliefs both in the nature of knowledge and in the process of knowing were included in the Epistemic Beliefs Instrument (SEB). The questionnaire devised by Conley et al. (2004) is the foundation of the SEB survey-in which students took part before the intervention. The reliability of the items in Conley et al.'s (2004) instrument ranged from 0.57 to 0.82 as far as the four SEB dimensions are concerned. Then, the convergent validity of the survey has a good model fit (CFI=0.90, RMSEA=0.038). The four measured dimensions were identified as Certainty, Source, Development, and Justification. The factor definitions are presented below:

Certainty: evaluating students' beliefs about the certainty of the answers for scientific knowledge, Source: assessing students' beliefs about the source of scientific knowledge from external authority, Development: assessing students' beliefs about scientific knowledge continuously evolving and changing and Justification: examining students' views on the role of experiments and the belief they have in justifying scientific knowledge (Tsai et al., 2011).

Items were rated on a 5-point Likert scale ( $1=$ strongly disagree; $5=$ strongly agree).

The Source dimension consists of five items, the Certainty dimension consists of six items, the Development dimension has six items and the Justification dimension consists of nine items. In order to measure the students' epistemological beliefs, the items of the Source and Certainty dimensions were reversed so that for each of the Dimensions, higher scores reflected more sophisticated beliefs. The Epistemological Belief Questionnaire was translated and adapted into Greek and the total reliability of the questionnaire is 0.67 . Students participated in the SEB Questionnaire before and after the intervention with the three software tools.

The Science Motivation Questionnaire (SMQ) used in the present study is based on social cognitive theory and is a revision of a previous SMQ questionnaire designed by Glynn et al. (2009) in order to improve its construct validity (Glynn et al., 2011).

After considering students' conceptualizations, intrinsic motivation, self-determination, self-efficacy, career motivation and grade motivation were assessed. For this purpose, the revised Science Motivation questionnaire (Glynn et al. 2009) was employed. This questionnaire aims to explore only positive, mutually supporting motivators. Therefore, items concerning self-efficacy are included whereas items concerning anxiety, which is a negative motivator are excluded. 
The final version of the Science Motivation Questionnaire (SMQ) consists of the following scales: intrinsic motivation, self-determination, self-efficacy, career-motivation and grade motivation. Each of these scales includes five items. The scales are short and the questionnaire could be completed in approximately fifteen minutes.

Students responded-before the intervention to SMQ. Items were rated on a 5-point Likert: never (1), rarely (2), sometimes (3), often (4), or always (5). The possible score range on each of the 5-item scales varies between 1 and 25. Some Questionnaire questions are "The science I learn is relevant to my life", "I like to do better than other students on science tests", and "I will use science problem-solving skills in my career". From the last question, we notice that problem -solving skills are considered as a prerequisite skill for the career.

A questionnaire was provided to students -before the intervention- to measure their understanding of Modelling indicators (systemic structure to interaction structure) in certain Physics phenomena. A two-hour discussion was held between the high school teacher, the author of the article and the students to explore the identified model types and their relationship to Hestenes' classification. Another questionnaire was given to the students after the intervention concentrating on the computational experiment approach and on the extent to which the presented models included Hestenes’ modelling indicators.

Students were exposed to models of simulation provided by the author of the article in the domains of oscillations using the repository (www.opensourcephysics.org) as well as other repositories with activities created with the Modellus and the Interactive Physics software.

For the Modelling indicators (systemic structure, geometric structure, temporal structure and interaction structure) four(4) stands for the fully favourable part (use of all indicators), three(3) for the use of three indicators (less favourable part), two(2) for the use of two indicators (partially favourable part) and one(1) for the use of one indicator (unfavourable part). Students discussed with the author the use of modelling indicators and before the intervention they were asked to recognize their existence in certain models.

All students participated in the ten two-hour courses. Students attended the K-12 class and the module of oscillations is going to be examined for their entrance at Greek Universities, mainly for the sectors of engineering and science as well as for the medicine school. During the course, the teacher started with applications which included the model development, the simulation method, the selection of the numerical method to be used in order to end in an algorithm and to finally implement it using one type of software following the methodology of the computational experiment.

After the intervention, students took an exam and their learning performance was assessed through a questionnaire provided by the author of this article and the high school teacher. The test included high order thinking, conceptual understanding and five problems covering all the material taught. It is important to state that the model was pervasive in the problems included at the final exam, while the problems were presented in alignment with the process of the computational experiment, i.e. students were asked to construct the model, to select the numerical method and to write the pseudo code for the model.

\subsection{Some applications}

We present some snapshots of the learning environments.

Applications in Interactive Physics -Modellus and EJS for the phenomenon of Oscillations developed through the Course by the author in collaboration with the high school teacher.

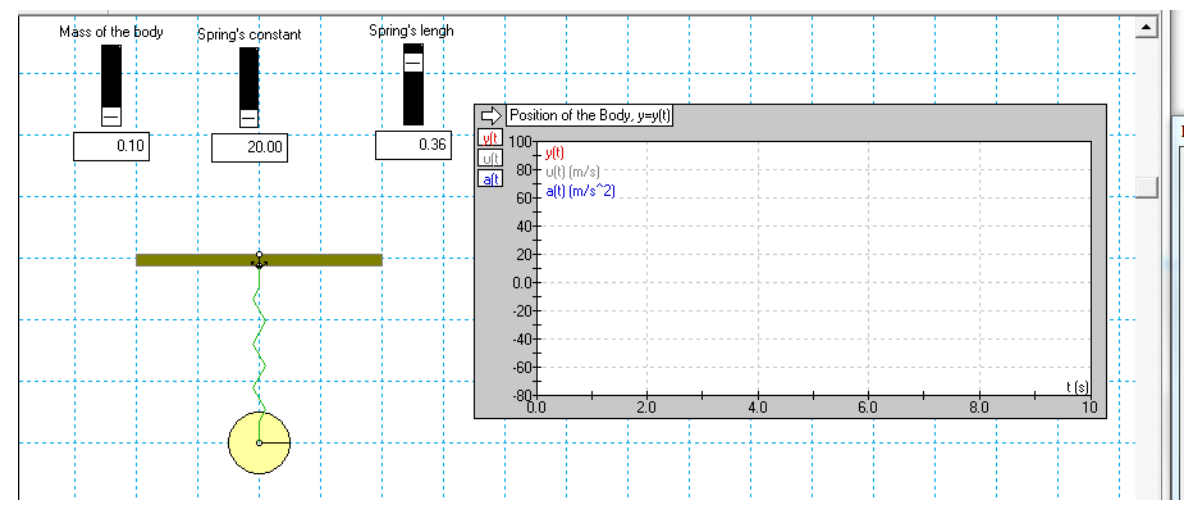

Figure 1. Oscillation using Interactive Physics 


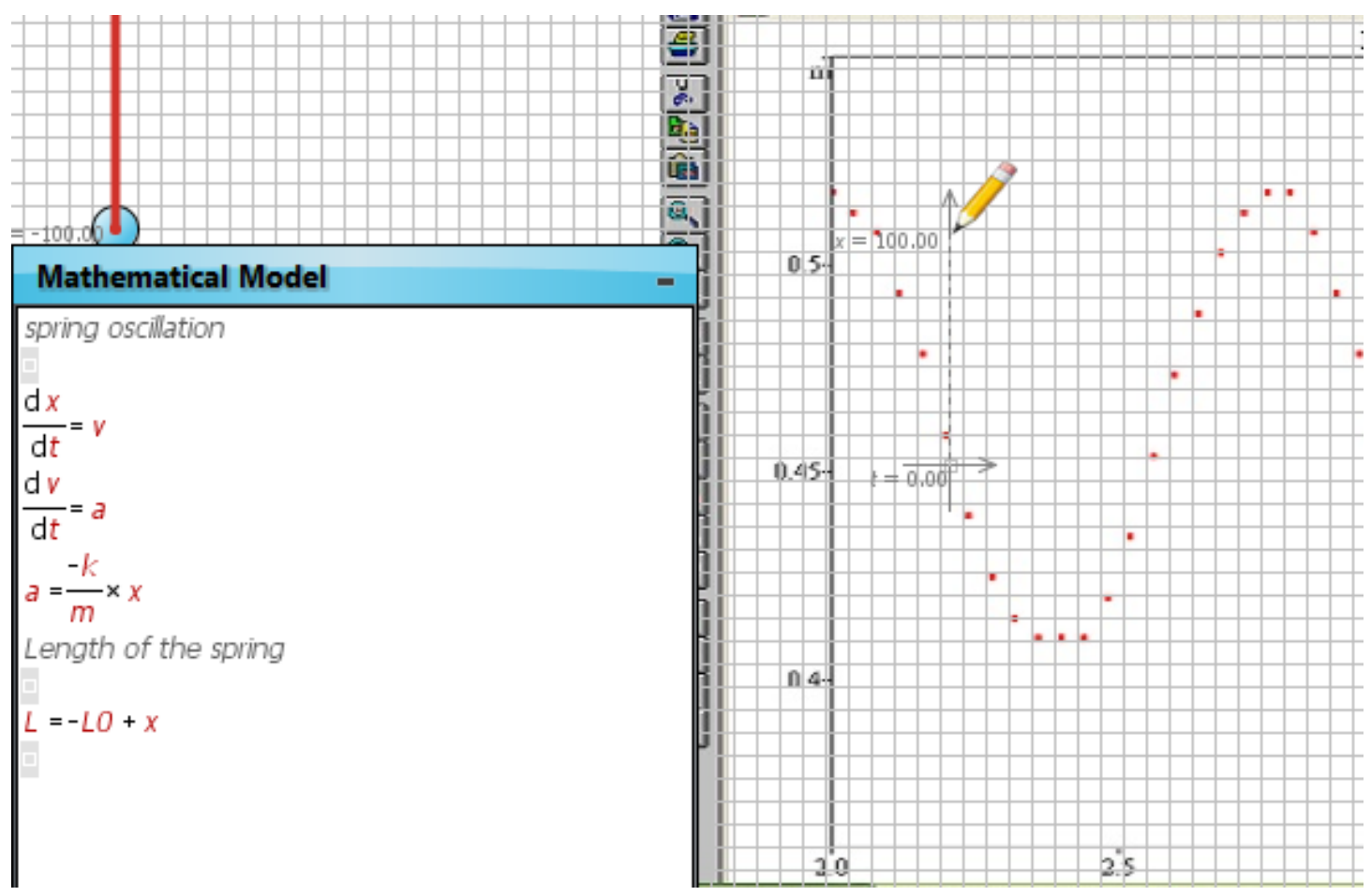

Figure 2. Mathematical modeling in Modellus

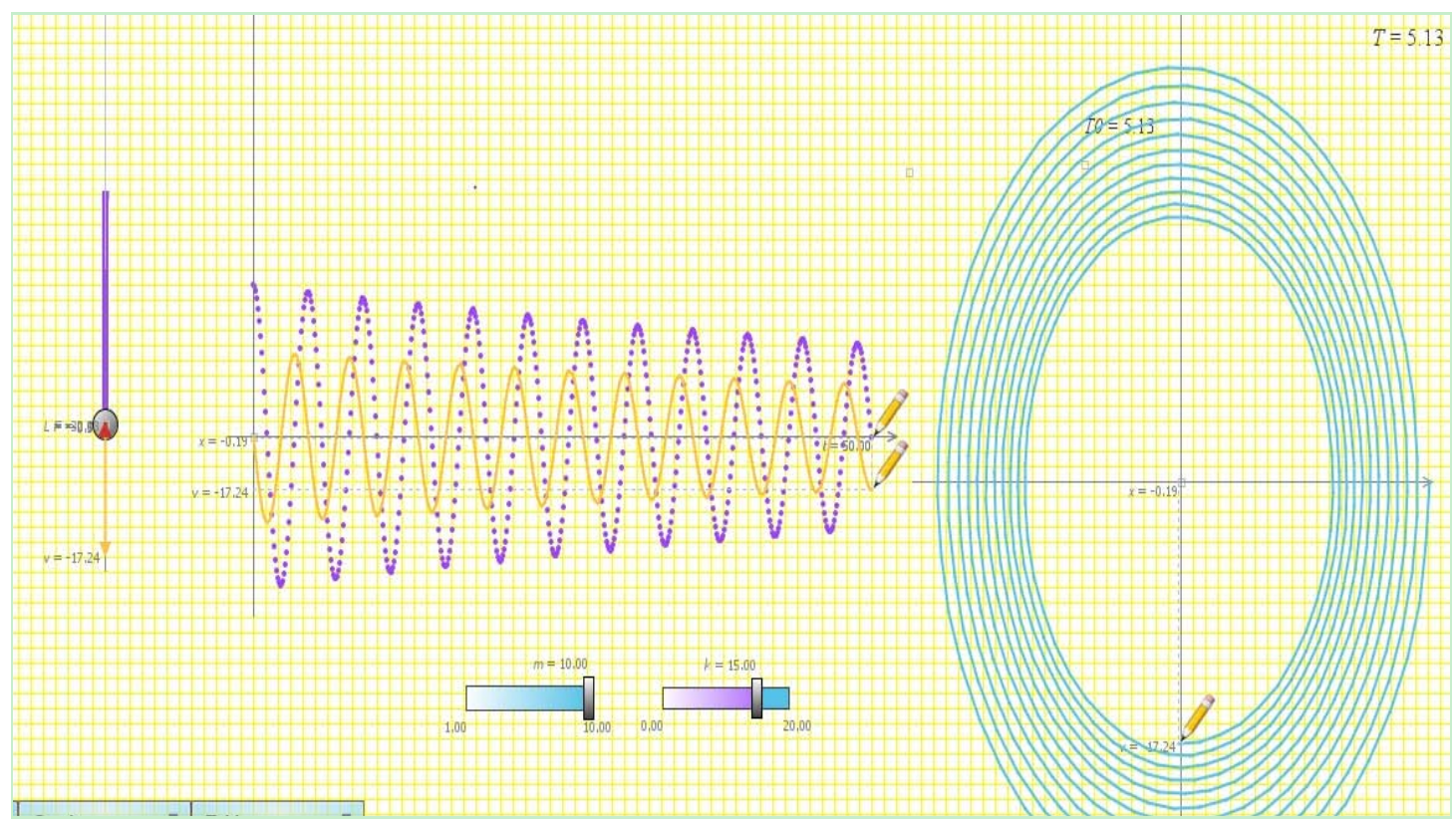

Figure 3. Simple Harmonic Motion using Modellus 


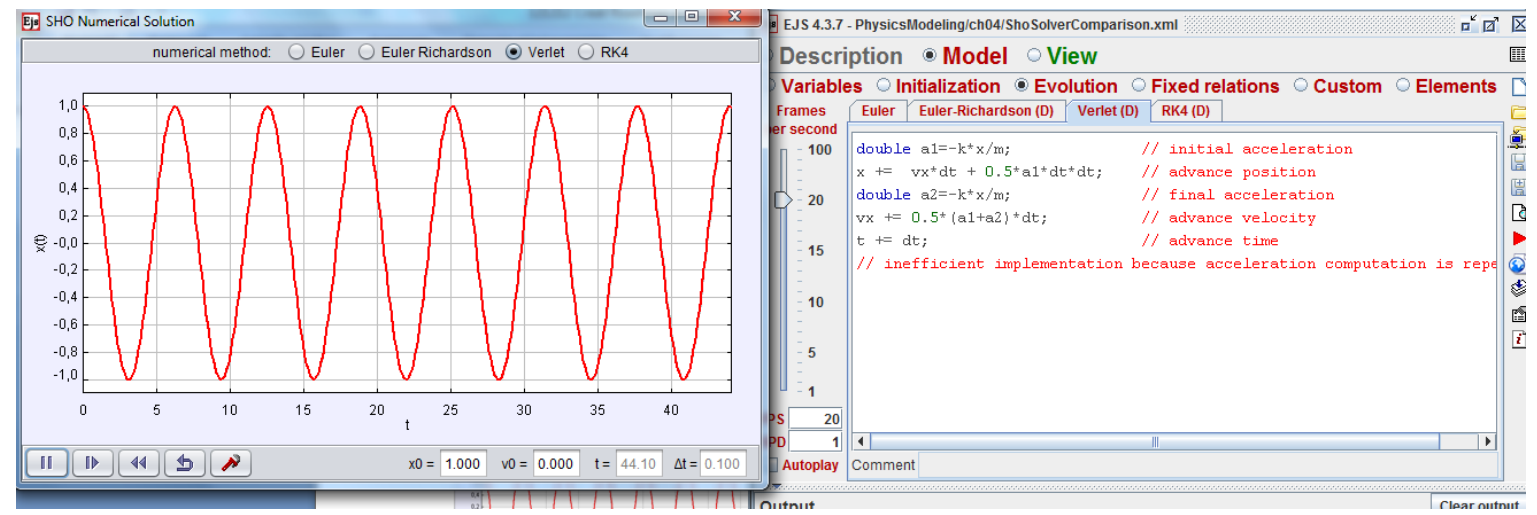

Figure 4. EJS simulation using the Verlet algorithm

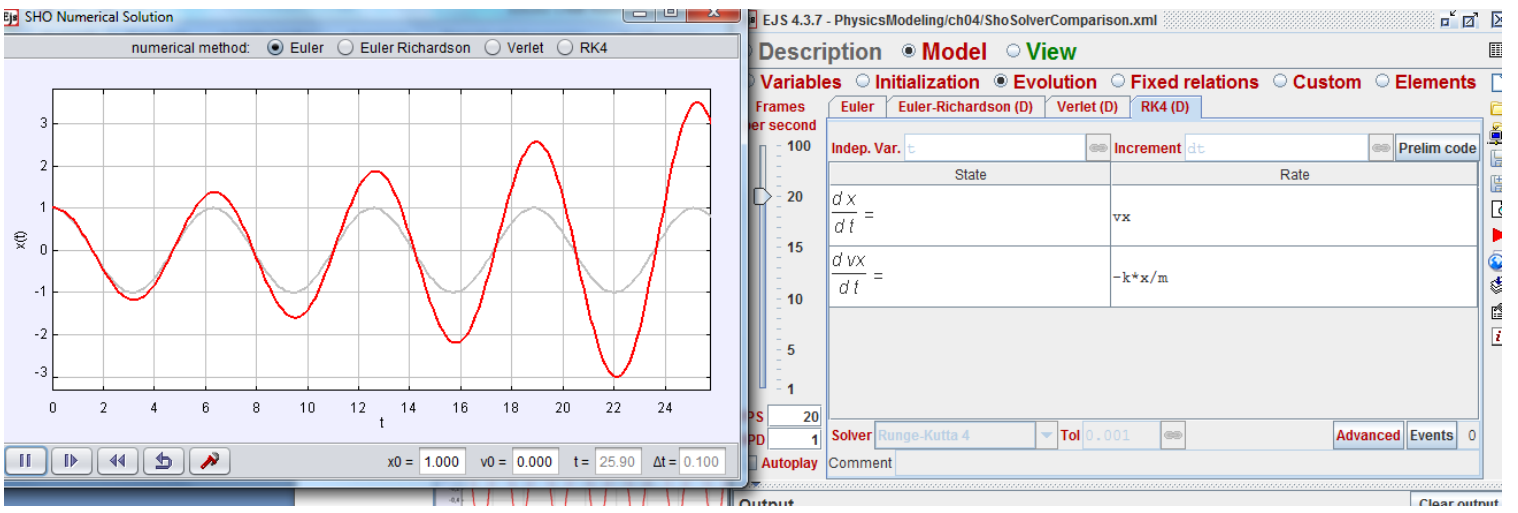

Figure 5. EJS Simulation using the Runge Kutta algorithm

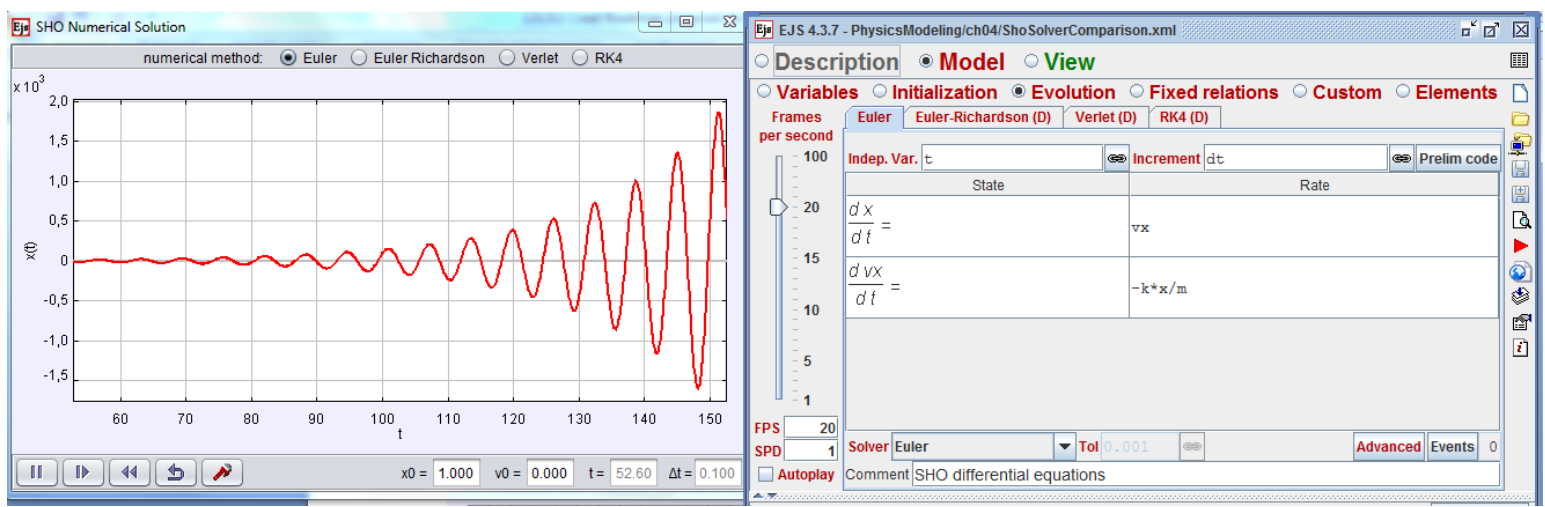

Figure 6. EJS Simulation using the Euler algorithm

\section{Results}

\subsection{Descriptive Statistics}

In the current study, 93 students participated in this study. The students were divided into three different clusters, according to the type of software they used. In Table 1 we present the descriptive information per group of students (for the epistemic beliefs, and the different components of the MSQ the results are before the intervention). Data are expressed as mean + standard deviation, while minimum and maximum values are also presented. No missing values appeared during the analysis. 
Table 1. Descriptive Statistics for the quantitative variable of the study, per software

\begin{tabular}{lllll}
\hline & N & Mean + S.D. & min & max \\
\hline IP Software & & & & \\
\hline Epistemic beliefs & 31 & $76.09+33.34$ & 23 & 125 \\
Learning performance & 31 & $55.48+25.14$ & 20 & 95 \\
Intrinsic motivation & 31 & $17.25+6.02$ & 7 & 25 \\
Career motivation & 31 & $18.38+5.84$ & 5 & 25 \\
Self determination & 31 & $16.35+4.99$ & 8 & 25 \\
Self-efficacy & 31 & $14.48+4.76$ & 6 & 22 \\
Grade motivation & 31 & $18.87+3.37$ & 13 & 25 \\
\hline Modellus Software & & & & \\
\hline Epistemic beliefs & 31 & $75.87+33.77$ & 22 & 128 \\
Learning performance & 31 & $64.19+20.74$ & 30 & 95 \\
Intrinsic motivation & 31 & $16.87+5.93$ & 7 & 25 \\
Career motivation & 31 & $18.25+5.81$ & 5 & 25 \\
Self determination & 31 & $16.41+4.98$ & 8 & 25 \\
Self-efficacy & 31 & $14.54+4.69$ & 6 & 22 \\
Grade motivation & 31 & $18.82+3.51$ & 13 & 25 \\
\hline Ejs Software & & & & \\
\hline Epistemic beliefs & 31 & $76.06+34.68$ & 22 & 128 \\
Learning performance & 31 & $75.00+14.77$ & 35 & 95 \\
Intrinsic motivation & 31 & $17.01+5.98$ & 7 & 25 \\
Career motivation & 31 & $17.78+5.81$ & 5 & 25 \\
Self determination & 31 & $16.79+4.98$ & 8 & 25 \\
Self-efficacy & 31 & $14.96+4.67$ & 6 & 22 \\
Grade motivation & 31 & $18.62+3.51$ & 13 & 25 \\
\hline
\end{tabular}

Below, we also present the histograms per variable and cluster from which we verify the use of parametric methods. Kolmogorov-Smirnoff test for all quantitative variables also verifies the normality of their distribution.

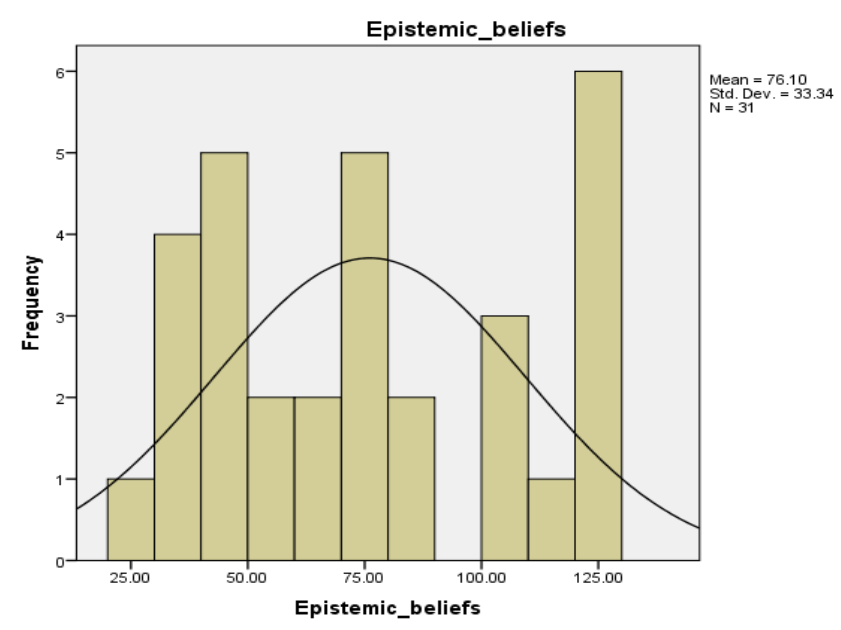

Figure 7. Distribution for Epistemic Beliefs -IP 


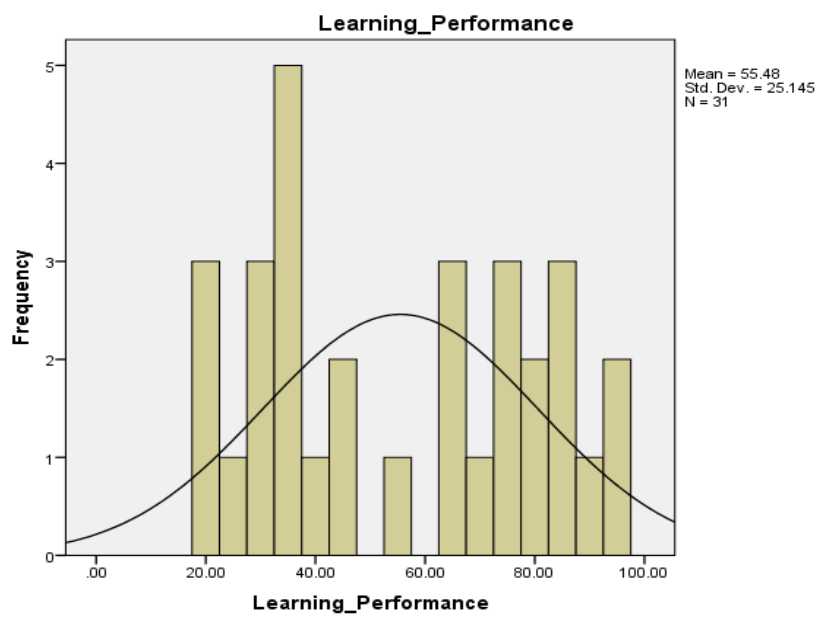

Figure 8. Distribution for Learning Performance-IP

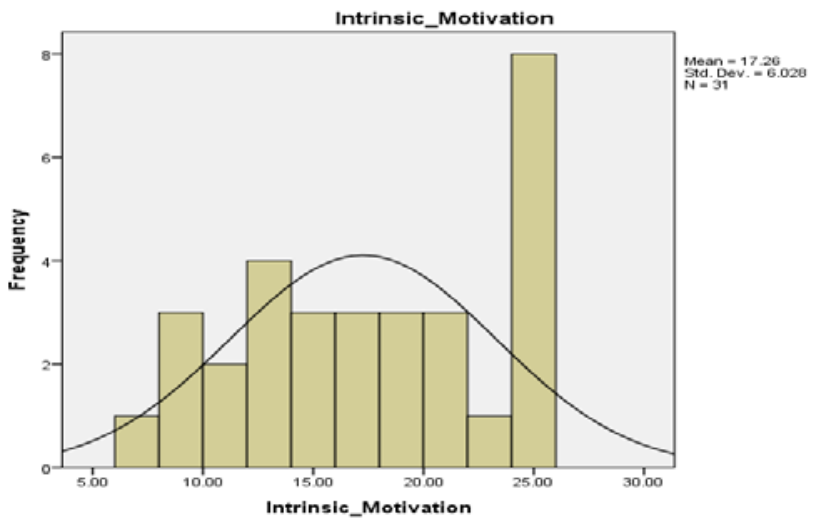

Figure 9. Distribution for Intrinsic Motivation-IP

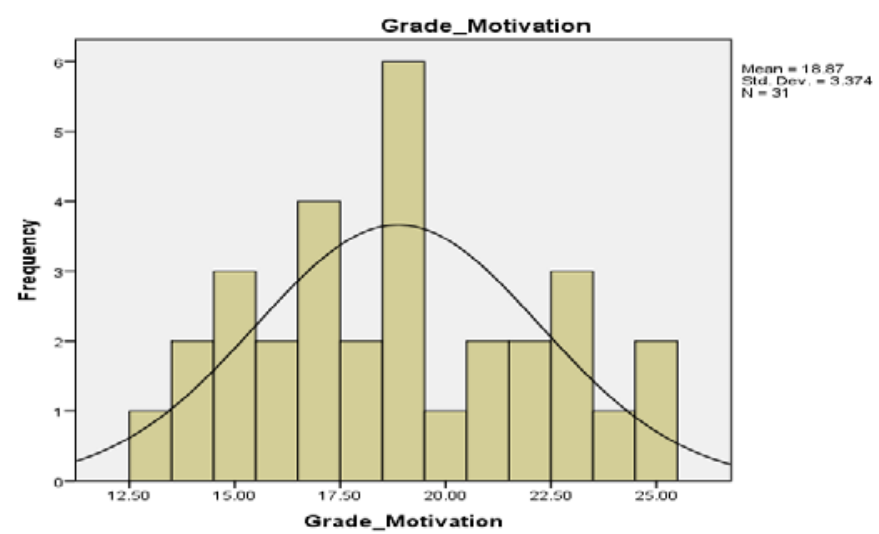

Figure 10. Distribution for Grade Motivation -IP 


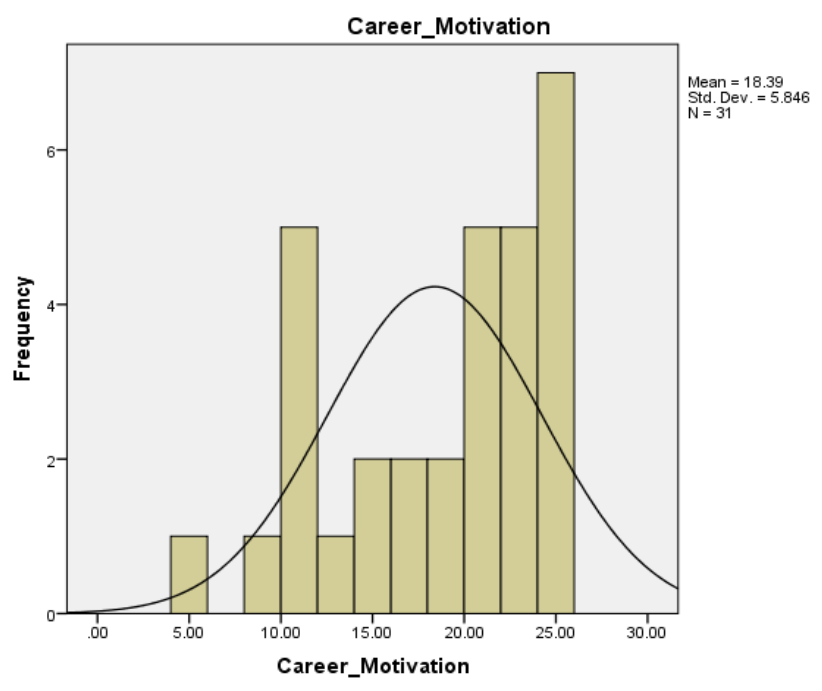

Figure 11. Distribution for Caree Motivation -IP

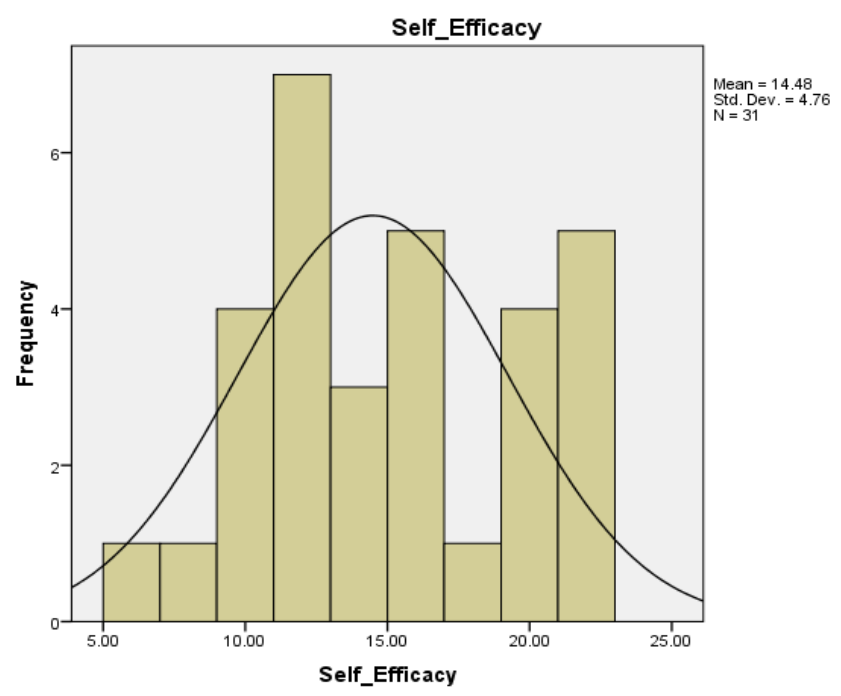

Figure 12. Distribution for Self -Efficacy -IP

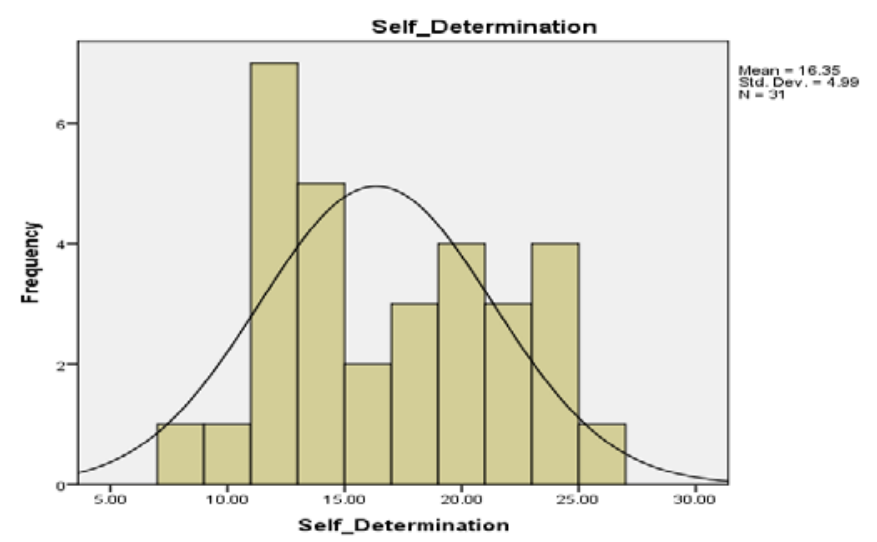

Figure 13. Distribution for Self Determination -IP 
The distributions for the other two software tools are similar and for this reason we do not present them.

In Table 2, we present the frequencies for the modelling indicators, per software.

Table 2. Descriptive Statistics concerning the categorical variables, per cluster

\begin{tabular}{lllll}
\hline & Frequency & Percent & Valid Percent & Cumulative Percent \\
\hline IP Software & & & & \\
\hline Modeling Indicators before & & & & \\
1 & 13 & 41.9 & 41.9 & 41.9 \\
2 & 5 & 16.1 & 16.1 & 58.1 \\
3 & 11 & 35.5 & 35.5 & 93.5 \\
4 & 2 & 6.5 & 6.5 & 100.0 \\
Total & 31 & 100.0 & 100.0 & \\
\hline Modeling Indicators after & & & & \\
1 & 9 & 29.0 & 29.0 & 29.0 \\
2 & 7 & 22.6 & 22.6 & 51.6 \\
3 & 10 & 32.3 & 32.3 & 83.9 \\
4 & 5 & 16.1 & 16.1 & 100.0 \\
Total & 31 & 100.0 & 100.0 & \\
\hline
\end{tabular}

\section{Modellus Software}

Modeling Indicators before

\begin{tabular}{lllll}
1 & 13 & 41.9 & 41.9 & 41.9 \\
2 & 5 & 16.1 & 16.1 & 58.1 \\
3 & 11 & 35.5 & 35.5 & 93.5 \\
4 & 2 & 6.5 & 6.5 & 100.0 \\
Total & 31 & 100.0 & 100.0 & \\
\hline Modeling Indicators after & & & & \\
1 & 6 & 19.4 & 19.4 & 19.4 \\
2 & 7 & 22.6 & 22.6 & 41.9 \\
3 & 10 & 32.3 & 32.3 & 74.2 \\
4 & 8 & 25.8 & 25.8 & 100.0 \\
Total & 31 & 100.0 & 100.0 & \\
\hline
\end{tabular}

\section{EJS Software}

Modeling Indicators before

\begin{tabular}{lllll}
1 & 15 & 48.4 & 48.4 & 48.4 \\
2 & 5 & 16.1 & 16.1 & 64.5 \\
3 & 11 & 35.5 & 35.5 & 100.0 \\
Total & 31 & 100.0 & 100.0 & \\
\hline Modeling Indicators after & & & & \\
1 & 1 & 3.2 & 3.2 & 3.2 \\
2 & 5 & 16.1 & 16.1 & 19.4 \\
3 & 13 & 41.9 & 41.9 & 61.3 \\
4 & 12 & 38.7 & 38.7 & 100.0 \\
Total & 31 & 100.0 & 100.0 & \\
\hline
\end{tabular}


The initial goal of the study is to explore whether the use of the three software tools discussed in the paper results is significant differences mainly in learning performance and modeling indicators. For this reason, we performed a t-test for all the quantitative variables. The relevant tests were performed in groups of two, in order to identify the exact significant differences. In Table 3 the results are presented. All tests were performed in a $95 \%$ confidence interval.

Table 3. Results of t-test between clusters of software

\begin{tabular}{lll}
\hline IP - Modellus & t-test & p-value* \\
\hline Epistemic beliefs & 0.04 & 0.950 \\
Learning performance & 4.160 & $0.046^{*}$ \\
Intrinsic motivation & 0.000 & 1.000 \\
Career motivation & 0.01 & 0.970 \\
Self determination & 0.02 & 0.966 \\
Self -efficacy & 0.12 & 0.914 \\
Grade motivation & 0.159 & 0.692 \\
\hline IP - EJS & t-test & p-value* \\
\hline Epistemic beliefs & 0.124 & 0.726 \\
Learning performance & 22.190 & $<0.001^{* *}$ \\
Intrinsic motivation & 0.000 & 1.000 \\
Career motivation & 0.01 & 0.970 \\
Self determination & 0.02 & 0.966 \\
Self -efficacy & 0.12 & 0.914 \\
Grade motivation & 0.159 & 0.692 \\
\hline Modellus - EJS & t-test & p-value* \\
\hline Epistemic beliefs & 0.081 & 0.776 \\
Learning performance & 5.641 & $0.021^{*}$ \\
Intrinsic motivation & 0.000 & 1.000 \\
Career motivation & 0.000 & 1.000 \\
Self determination & 0.000 & 1.000 \\
Self -efficacy & 0.000 & 1.000 \\
Grade motivation & 0.000 & 1.000 \\
\hline$*$ L & &
\end{tabular}

*5\% Level of significance, **1\% Level of significance

From the above table we notice that learning performance differs significantly between the three groups (clusters) of the study.

We also examined the correlations of learning performance with epistemic beliefs for each type of software. Using ANOVA, with the variables epistemic beliefs as independent variable and learning performance as dependent variable, we notice that: for the IP cluster $86.3 \%$ of total variance can be interpreted through the model, while, if we increase epistemic beliefs by one unit, learning performance for IP software users will be increased by 0.703 . Also, the correlation between the two variables is not only positive, but also statistically significant on a 99\% confidence interval. In Table 4.1, we can observe the specific results for this case:

Table 4.1. ANOVA model using learning performance as dependent and epistemic beliefs as independent, for IP group

\begin{tabular}{llllll}
\hline & B & Std. Error & Beta & t & p-value \\
\hline (Constant) & 2.020 & 4.219 & & 0.479 & 0.636 \\
Epistemic Beliefs & 0.703 & 0.051 & 0.932 & 13.798 & $<0.001$ \\
\hline
\end{tabular}


For the Modellus cluster, increasing epistemic beliefs by one unit, results in an increase in the Learning performance of this group by 0.798 . The particular model is able to interpret $84.6 \%$ of total variance.

Table 4.2. ANOVA model using learning performance as dependent and epistemic beliefs as independent, for Modellus group

\begin{tabular}{llllll}
\hline & B & Std. Error & Beta & t & p-value \\
\hline (Constant) & 26.402 & 5.524 & & 4.780 & $<0.001$ \\
Epistemic Beliefs & 0.798 & 0.067 & 0.811 & 7.469 & $<0.001$ \\
\hline
\end{tabular}

Concerning the third group of Software, the results of the model are presented in Table 4.3. The particular model interprets only $39.3 \%$ of total variance while, through it, we can conclude that increasing epistemic beliefs by one unit, we will have an increase in learning performance of EJS group by 0.774 units.

Table 4.3. ANOVA model using learning performance as dependent and epistemic beliefs as independent, for the EJS group

\begin{tabular}{llllll}
\hline & B & Std. Error & Beta & t & p-value \\
\hline (Constant) & 54.169 & 5.051 & & 10.724 & $<0.001$ \\
Epistemic Beliefs & 0.774 & 0.061 & 0.643 & 4.520 & $<0.001$ \\
\hline
\end{tabular}

From the above analysis we can see that epistemic beliefs (before the intervention) constitute an important factor associated with learning performance and positively correlating with it for all student clusters.

For the modelling indicators, for the IP software, the results are: the mean value before the intervention was $\mathrm{M}=2.06(\mathrm{SD}=1.031)$ and after the intervention $\mathrm{M}=2.35(\mathrm{SD}=1.082)$.

The $95 \%$ confidence interval of this difference has a range from -0.460 to $-0.121(t=-3.053, d f=30)$. Since the interval does not contain the zero the difference is statistically significant at $\mathrm{p}<0.005$ level.

For the modelling indicators, for the Modellus software, the results are: the mean value before the intervention was $\mathrm{M}=2.08$ ( $\mathrm{SD}=1.031$ ) and after the intervention $\mathrm{M}=2.40$ ( $\mathrm{SD}=1.082$ ).

The $95 \%$ confidence interval of this difference has a range from -0.845 to $-0.317(\mathrm{t}=-4.491, \mathrm{df}=30)$. Since the interval does not contain the zero the difference is statistically significant at $\mathrm{p}<0.005$ level.

For the modelling indicators, for the EJS software, the results are: the mean value before the intervention was $\mathrm{M}=2.03(\mathrm{SD}=0.922)$ and after the intervention $\mathrm{M}=3.16(\mathrm{SD}=0.820)$.

The $95 \%$ confidence interval of this difference has a range from -1.634 to $-0.946(t=-7.660, d f=30)$. Since the interval does not contain the zero the difference is statistically significant at $\mathrm{p}<0.005$ level.

For the MSQ questionnaire, after the intervention, we noticed significant changes only for the intrinsic motivation and the self-efficacy components.

For the case of IP software, the intrinsic motivation values are:

before the intervention $\mathrm{M}=17.25, \mathrm{SD}=6.02$ and after the intervention, $\mathrm{M}=17.95, \mathrm{SD}=5.77$. The $95 \%$ confidence interval of this difference has a range from -0.855 to $-0.176(t=-3.102, d f=30)$. Since the interval does not contain the zero the difference is statistically significant at $\mathrm{p}<0.005$ level.

For the case of IP software, the self-efficacy values are:

before the intervention $\mathrm{M}=14.48, \mathrm{SD}=4.76$ and after the intervention, $\mathrm{M}=16.06, \mathrm{SD}=4.83$. The $95 \%$ confidence interval of this difference has a range from -2.139 to $-1.022(t=5.780, d f=30)$. Since the interval does not contain the zero the difference is statistically significant at $\mathrm{p}<0.005$ level.

For the case of Modellus software, the intrinsic motivation values are:

before the intervention $\mathrm{M}=16.87, \mathrm{SD}=5.93$ and after the intervention, $\mathrm{M}=18.02, \mathrm{SD}=5.28$. The $95 \%$ confidence interval of this difference has a range from -2.033 to $-0.611(t=-3.798, d f=30)$. Since the interval does not contain the zero the difference is statistically significant at $\mathrm{p}<0.005$ level. 
For the case of Modellus software, the self-efficacy values are:

before the intervention $\mathrm{M}=14.54, \mathrm{SD}=4.69$ and after the intervention, $\mathrm{M}=16.87, \mathrm{SD}=4.65$. The $95 \%$ confidence interval of this difference has a range from -3.222 to $-1.422(\mathrm{t}=-5.268, \mathrm{df}=30)$. Since the interval does not contain the zero the difference is statistically significant at $\mathrm{p}<0.005$ level.

For the case of EJS software, the intrinsic motivation values are:

before the intervention $\mathrm{M}=17.01, \mathrm{SD}=5.98$ and after the intervention, $\mathrm{M}=19.58, \mathrm{SD}=5.28$. The $95 \%$ confidence interval of this difference has a range from -1.133 to $-0.578(\mathrm{t}=-3.211, \mathrm{df}=30)$. Since the interval does not contain the zero the difference is statistically significant at $\mathrm{p}<0.005$ level.

For the case of EJS software, the self-efficacy values are:

before the intervention $\mathrm{M}=14.96, \mathrm{SD}=4.67$ and after the intervention, $\mathrm{M}=18.09, \mathrm{SD}=4.22$. The $95 \%$ confidence interval of this difference has a range from -4.232 to $-2.025(\mathrm{t}=-5.791, \mathrm{df}=30)$. Since the interval does not contain the zero the difference is statistically significant at $\mathrm{p}<0.005$ level.

For the case of EJS software, the self-efficacy values are:

Before the intervention $\mathrm{M}=14.54, \mathrm{SD}=4.69$ and after the intervention, $\mathrm{M}=16.87, \mathrm{SD}=4.65$. The $95 \%$ confidence interval of this difference has a range from -3.222 to $-1.422(\mathrm{t}=-5.268, \mathrm{df}=30)$. Since the interval does not contain the zero the difference is statistically significant at $\mathrm{p}<0.005$ level.

After the results concerning the significant motivational factors (intrinsic motivation and self-efficacy), we decided to proceed by examining the correlation of learning performance only with the intrinsic motivation, the self-efficacy and the epistemic beliefs after the intervention, for each software.

For the case of IP, the results indicate that $84 \%$ of the learning performance is due to the epistemic beliefs $(B=0.73$, beta $=0.917, t=12.369, F 1,29=152.999, p<0.001)$

For the case of Modellus, the results indicate that $59 \%$ of the learning performance is due to the epistemic beliefs $(B=0.53$, beta $=0.762, t=6.372, F 1,29=40.601, p<0.001)$.

For the case of EJS, the results indicate that $39 \%$ of the learning performance is due to the epistemic beliefs $(B=0.314$, beta $=0.625, t=4.317, F 1,29=18.636, p<0.001)$.

For the case of IP software, the epistemic beliefs values before the intervention are: $\mathrm{M}=76.09, \mathrm{SD}=33.34$ and after the intervention, $\mathrm{M}=80.129$ and $\mathrm{SD}=31.60$.

The $95 \%$ confidence interval of this difference has a range from 1.839 to $6.483(t=3.660, \mathrm{df}=30)$. Since the interval does not contain the zero the difference is statistically significant at $\mathrm{p}<0.005$ level.

For the case of Modellus software, the epistemic beliefs values before the intervention are: $\mathrm{M}=75.87, \mathrm{SD}=33.77$ and after the intervention, $\mathrm{M}=84.41$ and $\mathrm{SD}=29.88$.

The $95 \%$ confidence interval of this difference has a range from 4.469 to $12.885(t=4.221, \mathrm{df}=30)$. Since the interval does not contain the zero the difference is statistically significant at $\mathrm{p}<0.005$ level.

For the case of EJS software, the epistemic beliefs values before the intervention are: $\mathrm{M}=76.06, \mathrm{SD}=34.68$ and after the intervention, $\mathrm{M}=88.22$ and $\mathrm{SD}=29.41$.

The $95 \%$ confidence interval of this difference has a range from 7.725 to $16.725(t=5.548, d f=30)$. Since the interval does not contain the zero the difference is statistically significant at $\mathrm{p}<0.005$ level.

\section{Discussion}

The central aim of the study was to demonstrate the impact of the computational experiment approach on epistemic beliefs, motive factors, modeling indicators and learning performance for three computational tools that are used internationally as modeling software tools.

The test results indicate that the EJS class outperformed the two IP and Modellus classes for the learning performance.

The results of the quantitative study also show a strong connection between the use of EJS and use of Modelling indicators. The difference in the mean values related to the EJS is significantly bigger than that of the IP and Modellus.

The computational experiment approach seems to have a strong impact on the shift of students' epistemological beliefs, as well as on two motivational features namely intrinsic motivation and the self-efficacy for the three clusters. 
Druger (2006) argues that one of the most important goals for the introductory science courses instructor is to help students become motivated self-learners. Results indicate that students consider items like "Learning science is interesting", "I enjoy learning science", "I believe I can earn a grade of "A" in science”, "I am sure I can understand science" important.

The MSQ questionnaire and the understanding of the process of the computational experiment can be used to identify highly motivated students. The above could be beneficial to instructors who wish to create groups that work collaboratively and ensure the existence of at least one highly motivated group member in the computational environment. The instructor can also request that these students act as group leaders, who encourage all team participants to engage fully in the work of the group.

Students who used the EJS software had better learning performance. We can attribute this to many factors.

Students at grade K-12 have a strong mathematical background and the concept of the derivate of a function was very fascinating to them. Students considered that EJS provided the means to change the model as well as to include mathematics concepts like derivatives and integrals. During the course the author and the high school teacher developed inquiry based learning scenarios based on the use of the three different software tools. In all of them the inquiry based method was employed and during the modeling process, instead of designing the course to address specific "naïve conceptions," the teacher focused on helping students construct appropriate models to account for the phenomena they studied.

Klahr and Dunbar (1988) characterized scientific thinking as a search in two problem spaces, a hypothesis space and an experiment space.

Computational approaches provide specific models of the cognitive processes underlying scientific thinking and building computational models of the reasoning processes involved in a domain can help the development of the experiment space.

Psycharis (2011) extended these spaces in order to include the computational experiment approach and suggested three spaces for the computational experiment, namely:

1. The hypotheses space, where the students in cooperation with the teacher, decide, clarify and state the hypotheses of the problem to be studied, as well as the variables and concepts to be used and the relations between these.

2. The experimental space, where the computational experiment actually takes place and includes modelling-simulation-based on discovery/inquiry learning activities for the problems under study, replaces the classical experimental and learners are engaged in the scientific method.

3. The prediction space, where the results, conclusions or solutions formulated in the experiments space, are checked with the analytical (mathematical) solution as well as with data from the real world and help learners towards predictions for other phenomena.

The three spaces of the computational experiment are connected with the essential features of Inquiry and the Inquiry tools used, as presented in Table 1.

Table 5. The connection between the spaces of the computational experiment, the inquiry features and the inquiry tools

\begin{tabular}{|c|c|c|}
\hline $\begin{array}{l}\text { Spaces of the Computational } \\
\text { Experiment(Psycharis, 2011) }\end{array}$ & $\begin{array}{l}\text { Essential Features of Inquiry } \\
\text { (Assay \& Orgill, 2010) }\end{array}$ & Inquiry tools of (Bell et.al, 2010) \\
\hline Hypotheses space & Question & $\begin{array}{l}\text { Orienting and asking questions; } \\
\text { generating hypotheses }\end{array}$ \\
\hline \multirow[t]{3}{*}{ Experimental space } & Evidence Analyze & Planning-Investigating \\
\hline & Explain & Analysis and interpretation \\
\hline & & Modelling \\
\hline \multirow[t]{2}{*}{ Prediction Space } & Connect & Conclusion-Evaluation-Prediction \\
\hline & Communicate & \\
\hline
\end{tabular}


During the course, students were exposed to learning scenarios employing the IBSE( inquiry based science education). The author and the teacher explained to students the inquiry process, the role of modeling as well as the ways of connecting the above mentioned spaces, the IBSE features and the inquiry tools with Hestenes' modeling indicators. The results from the final exam revealed that students who used EJS seemed to have the capacity to collect data (the evidence feature of Inquiry process), to analyze the data and to explain it based on the model of oscillations. EJS class students, in general, appeared to be interested in attending the inquiry process and were also more active in participating in science activities and in using inquiry tools to investigate the phenomena under study. They were also involved in the prediction space, as they suggested new forms of oscillations and they connected phenomena of real life to mathematical modelling of oscillations. Students who used EJS made a lot of hypotheses during the construction of models and they also used some numerical analysis features provided by the EJS environment.

Based on the research and the analysis of the data, this study does not only have significant practical implications for the physics educators at secondary level in Greece, but also contributes to the current literature related to the use of computational software and its use for students' engagement in inquiry tools and processes. The findings of this study can also be used to inform science education researchers about the integration of modeling instruction in secondary physics and science classes and about the construction and application of conceptual models of physical phenomena as a central aspect of learning and doing science (Hestenes, 1999). Models and modeling as a unifying theme for science and mathematics education can be elaborated using different kinds of software, but software providing the opportunity to develop expressive models, and not only explorative models, seem to advance students capacity to create their own models. EJS can be effective in producing students who engage intelligently in debate about matters of scientific and technical concern, while IP and Modellus seem to be more suitable for visual representations and development of explorative models.

\section{References}

Asay, L. D., \& Orgill, M. K. (2010). Analysis of essential features of inquiry found in articles published in The Science Teacher, 1998-2007. Journal of Science Teacher Education, 21, 57-79. http://dx.doi.org/10.1007/s10972-009-9152-9

Bandura, A. (2006). Going global with social cognitive theory: From prospect to paydirt. In S. I. Donaldson, D. E. Berger \& K. Pezdek (Eds.), The rise of applied psychology: New frontiers and rewarding careers (pp. 53-70). Mahwah, NJ: Erlbaum.

Barton, R., \& Haydn, T. (2006). Trainee teachers' views on what helps them to use information and communication technology effectively in their subject teaching. Journal of Computer Assisted Learning, 22, 257-272. http://dx.doi.org/10.1111/j.1365-2729.2006.00175.x

Bell, P. L., Hoadley, C., \& Linn, M. C. (2004). Design-based research as educational inquiry. In M. C. Linn, E. A. Davis \& P. L. Bell (Eds.), Internet environments for science education. Mahwah, NJ: Lawrence Erlbaum Associates.

Bell, T., Urhahne, D., Schanze, S., \& Ploetzner, R. (2010). Collaborative inquiry learning: models, tools and challenges. International Journal of Science Education, 32(3), 349-377. http://dx.doi.org/10.1080/09500690802582241

Bybee, R. W., Trowbridge, L. W, \& Powell, J. C. (2008). Teaching Secondary School Science: Strategies for Developing Scientific Literacy. New Jersey: Merrill.

Conley, A. M., Pintrich, P. R., Vekiri, I., \& Harrison, D. (2004). Changes in epistemological beliefs in elementary $\begin{array}{llll}\text { science students. Contemporary Educational Psychology, 29, 186-204. } & \text {. }\end{array}$ http://dx.doi.org/10.1016/j.cedpsych.2004.01.004

Druger, M. (2006). Experiential learning in a large introductory biology course. In J. J. Mintzes \& W. H. Leonard (Eds.), Handbook of college science teaching (pp. 37-43). Arlington, VA: National Science Teachers Association Press.

Ericsson, K. A. (2006). The influence of experience and deliberate practice on the development of superior expert performance. In K. A. Ericsson, N. Charness, P. Feltovich, \& R. R. Hoffman (Eds.), Cambridge handbook of expertise and expert performance (pp. 685-706). Cambridge UK: Cambridge University Press. http://dx.doi.org/10.1017/CBO9780511816796.038

Glynn, S. M., \& Koballa T. R. (2006). Motivation to learn in college science. In J.J. Mintzes \& W.H. Leonard (Eds.), Handbook of College Science Teaching (pp. 25-32). Arlington VA, USA: NSTA Press. 
Glynn, S. M., Taasoobshirazi, G., \& Brickman, P. (2007). Nonscience majors learning science: A theoretical model of motivation. Journal of Research in Science Teaching, 44, 1088-1107. http://dx.doi.org/10.1002/tea.20181

Glynn, S. M., Taasoobshirazi, G., \& Brickman, P. (2009). Science motivation questionnaire: Construct validation with nonscience majors. Journal of Research in Science Teaching, 46, 127-146. http://dx.doi.org/10.1002/tea.20267

Glynn, S. M., Amstrong, N., Brickman, P., \& Taasoobshirazi, G. (2011). Science Motivation Questionnaire II: Validation with Science Majors and Nonscience Majors. Journal of Research in Science Teaching, 48, 1159-1176. http://dx.doi.org/10.1002/tea.20442

Halloun, I. (2006). Modelling Theory in Science Education. Dordrecht: Kluwer Academic Publishers/Springer.

Hestenes, D. (1999). The scientific method. American Journal of Physics, 67, 273-276. http://dx.doi.org/10.1119/1.19243

Hofer, B. K. (2000). Dimensionality and disciplinary differences in personal epistemology. Contemporary Educational Psychology, 25, 378-405. http://dx.doi.org/10.1006/ceps.1999.1026

Hofer, B. K., \& Pintrich, P. R. (1997). The development of epistemological theories: Beliefs about knowledge and knowing and their relation to learning. Review of Educational Research, 67, 88-140.

Kienhues, D., Bromme, R., \& Stahl, E. (2008). Changing epistemological beliefs: the unexpected impact of a short-term intervention. British Journal of Educational Psychology, 78, 545-565, http://dx.doi.org/10.1348/000709907X268589

Klahr, D., \& Dunbar, K. (1998). Dual space search during scientific reasoning. Cognitive Science, 12, 1-48. http://dx.doi.org/10.1207/s15516709cog1201_1

Kurt, F. (2009). Investigating students' epistemological beliefs through gender, grade level, and fields of the study. A thesis submitted to the graduate school of social sciences of the Middle East Technical University. Retrieved from https://etd.lib.metu.edu.tr/upload/12611181/index.pdf

Landau, R. H., Páez, J., \& Bordeianu, C. (2008). A Survey of computational physics introductory computational science. New Jersey: Princeton University Press.

Levy, P., Little, S., McKinney, P., Nibbs, A., \& Wood, J. (2010). The Sheffield companion to inquiry-based learning. Sheffield, UK: Centre for Inquiry-based Learning in the Arts and Social Sciences, The University of Sheffield.

Minner, D., Levy, A. J., \& Century, J. (2010). Inquiry-based science instructrion - What is it and does it matter: Results from a research synthesis years 1984 to 2002. [Science Education]. Journal of Research in Science Teaching, 47(4), 474-496. http://dx.doi.org/10.1002/tea.20347

Muis, K. R., \& Franco, G. M. (2009). Epistemic beliefs: setting the standards in self regulated learning. Contemporary Educational Psychology, 34, 306-318. http://dx.doi.org/10.1016/j.cedpsych.2009.06.005.

Pajares, F., \& Schunk, D. H. (2001). Self-beliefs and school success: Self-efficacy, self- concept, and school achievement. In R. Riding \& S. Rayner (Eds.), BT self-perception (pp. 239-266). London: Ablex Publishing.

Pintrich, P. R., \& Schunk, D. H. (2002). Motivation in education: Theory, research, and applications. Upper Saddle River, NJ: Pearson/Merrill Prentice Hall.

Perry, W. G., Jr. (1970). Forms of intellectual and ethical development in the college years: A scheme. New York: Holt, Rinehart and Winston.

Psycharis, S. (2011). The computational experiment and its effects on approach to learning and beliefs on physics. Computers \& Education, 56, 547-555. http://dx.doi.org/10.1016/j.compedu.2010.09.011

Rodrigues, S. (2003). Experiences from the partnership in primary science project: Teacher professional development involving ICT and science pedagogical content knowledge. Science Education International, 14(2), 2-11.

Rotgans, I. (2009). Motivation, Achievement-Related Behaviours, and Educational Outcomes. PhD thesis. Retrieved from http://ebookbrowse.com/phd-thesis-rotgans-pdf-d44269454.

Ryan, R. M., \& Deci, E. L. (2000). Intrinsic and extrinsic motivations: Classic definitions and new directions. Contemporary Educational Psychology, 25, 54-67. http://dx.doi.org/10.1006/ceps.1999.1020 
Schommer, M. (1990). Effects of beliefs about the nature of knowledge on comprehension. Journal of Eucational Psychology, 82(3), 498-504. http://dx.doi.org/10.1037/0022-0663.82.3.498

Schommer, M. (1993). Epistemological Development and Academic Performance Among Secondary Students. Journal of Educational Psychology, 85(3), 406-411. http://dx.doi.org/10.1037/0022-0663.85.3.406

Shunn, C., \& Klahr, D. (1995). A 4-space model for scientific discovery. Paper presented at the AAAI Symposium Systematic Methods of Scientific Discovery, Menlo Park, CA.

Shulman, L. S. (1987). Knowledge and teaching: Foundations of the new reform. Harvard Educational Review, 57(1), $1-22$.

Taasoobshirazi, G., \& Carr, M. (2009). A structural equation model of expertise in college physics. Journal of Educational Psychology, 101(3), 630-643. http://dx.doi.org/10.1037/a0014557

Tsai, C. C., Ho, H. N. J., Liang, J. C., \& Lin, H. M. (2011). Scientific epistemic beliefs, conceptions of learning science and self-efficacy of learning science among high school students. Learning and Instruction, 21(6), 757-769.

Valanides, N., \& Angeli, C. (2005, in press). Learning by Design as an Approach for Developing Science Teachers' ICT-Related Pedagogical Content Knowing. In S. Rodrigues (Ed.), International Models of Teacher (primary, secondary and tertiary) Professional Development (pp. 79-101). New York, NY: Nova Science.

\section{(cc) EY}

This work is licensed under a Creative Commons Attribution 3.0 License. 